[Agr. Biol. Chem., Vol. 33, No. 7, p. 1001 1006, 1969]

\title{
Influence of Dietary Carbohydrate, Fat, and Protein on Lipogenesis in Rats
}

\author{
By Toshizo KImURA* and Kiyoshi Ashida \\ Laboratory of Nutritional Biochemistry, Department of Agricultural \\ Chemistry, Nagoya University, Chikusa-ku, Nagoya \\ Received November 5, 1968
}

\begin{abstract}
The incorporation of ${ }^{14} \mathrm{C}$ of acetate-1-14 $\mathrm{C}$ into the lipids of the liver and carcass, and the changes in the concentrations of nucleotides and citric acid in the liver were studied in the rats fed individual nutrients; starch, casein or corn oil. And the metabolism of citric acid-1,5-14 $\mathrm{C}$ was also investigated after the feeding of nutrients. Lipogenesis in the liver and carcass was more markedly stimulated with starch than with casein or corn oil. In the liver of rats fed starch, the concentration of ATP doubled and that of citric acid was one-half of those with casein or corn oil, respectively. And the conversion of citric acid to carbon dioxide and lipids was stimulated with starch.
\end{abstract}

In the previous paper, ${ }^{11}$ it was reported that lipogenesis was stimulated with an increase in the content of starch both in the starch-casein or starch-corn oil diets, as shown by determination of the incorporation of ${ }^{14} \mathrm{C}$ of acetate$1-{ }^{14} \mathrm{C}$ into the lipids of the liver and carcass of rats fed diets containing starch and casein, or starch and corn oil at different ratio. Furthermore, the level of ATP increased and that of citric acid decreased with an increase in lipogenesis in the liver.

The present work was carried out to study the effect of individual nutrients, such as carbohydrate, fat, and protein, on lipogenesis in rats, and the relationship between these effects and the concentrations of nucleotides and citric acid in the liver, and between these effects and citric acid metabolism in the rats.

\section{EXPERIMENTAL}

Experimental animals. Male rats of the WistarDonryu strain weighing approximately $150 \mathrm{~g}$ were

* Present address: Laboratory of Food and Nutrition, Faculty of Science of Living, Osaka City University, Sumiyoshi-ku, Osaka. trained for 2 weeks to consume a $25 \%$ casein diet" for only $2 \mathrm{hr}$ a day.

Experiment 1. After the training period, the rats were divided into 4 groups. One group was killed before experimental feeding. The other 3 groups were given $5 \mathrm{~g}$ of $\alpha$-starch, $5 \mathrm{~g}$ of casein, and $2 \mathrm{~g}$ of corn oil with $3 \mathrm{~g}$ of cellulose powder, respectively. Each of the nutrients, containing nearly the same amount of calories, was consumed within $2 \mathrm{hr}$. After the end of $2 \mathrm{hr}$ of feeding, the rats of each group were injected intraperitoneally with $10 \mu \mathrm{Ci}$ of acetate-1 $14 \mathrm{C}$, having a specific activity of $10.0 \mathrm{mCi} / \mathrm{mmole}$, and placed immediately in a metabolic chamber. The respiratory carbon dioxide was collected by trapping into $2 \mathrm{~N}$ sodium hydroxide solution. One hour later the rats were decapitated. The livers were quickly removed from them, placed in acetone containing solid carbon dioxide, and used for analysis. The carcasses, from which the dietary residue in the stomach had been removed, were kept in a deep freezer until they were used for analysis. The frozen carcasses were ground by passing through a meat grinder several times. The radioactivities of the carbon dioxide and lipids in the liver and carcass, and the amounts of glycogen and nucleotides in the liver were measured by the same

1) T. Kimura and K. Ashida, Agr. Biol, Chem. 33, 915 (1969). 
methods as those described in the previous paper. ${ }^{11}$ The results on the incorporation of ${ }^{14} \mathrm{C}$ were shown with the relative recovery ratio, which was obtained by comparing the radioactivity of each of the three fractions, i.e., the respiratory carbon dioxide, the lipids of the liver, and those of the carcass, with the sum total of radioactivity found these three fractions.

Experiment 2. Rats trained in such manner as mentioned above were used. After the training period, they fed the nutrients for $2 \mathrm{hr}$ a day as in Experiment 1. The rats were decapitated 2,6 and $18 \mathrm{hr}$ later. The livers were quickly removed from them, placed in acetone containing solid carbon dioxide, and used to assay the concentration of nucleotides in the same manner as in Experiment 1.

Experiment 3. As in Experiment 1 and 2, rats were trained and fed three nutrients for $2 \mathrm{hr}$ a day. They were decapitated $1 \mathrm{hr}$ later. The livers were quickly removed, placed in acetone containing solid carbon dioxide, and used to assay the concentration of citric acid by the method of Saffran and Denstedt. ${ }^{2}$ In addition, some liver samples were treated with acetic anhydride and pyridine, cooled then in ice-water, and centrifuged in order to remove the turbidity of glycogen. The concentration of citric acid was determined by measuring the absorption at $420 \mathrm{~m} \mu$ of the resulting supernatant.

Experiment 4. Rats trained as mentioned above were fed the three nutrients in the same manner as in Experiment 1,2 and 3. Then they were injected intraperitoneally with $5 \mu \mathrm{Ci}$ of citric acid-1,5-14 $\mathrm{C}$. having a specific activity $3.0 \mathrm{mCi} / \mathrm{mmole}$, and placed immediately in a metabolic chamber. The respiratory carbon dioxide was collected by trapping in $2 \mathrm{~N}$ sodium hydroxide solution. Thirty minutes later the rats were decapitated and the livers were removed from them. In order to assay the total activity of ${ }^{14} \mathrm{C}$ in the liver or the carcass, the pooled pieces of each tissue from 4 animals were immersed in 3 volumes of $1 \%$ sodium hydroxide solution, heated for digestion, and then cooled. After neutralization, water was added to the solution to make up a definite volume. The aliquot was plated for counting. In order to assay the activity of ${ }^{14} \mathrm{C}$ in the $5 \%$ trichloroacetic acid-soluble fraction in the liver and the carcass, the pooled pieces of each

2) M. Saffran and O.F. Densted, J. Biol. Chem., $175,849(1948)$ tissue from 4 animals were homogenized with 5 volumt of $5 \%$ trichloroacetic acid solution two times an centrifuged. The resulting supernatant was neutralize and made up to a definite volume. The aliquot wa mixed an equal volume of $5 \%$ gelatin solution, an the mixture was plated for counting.

The amounts and radioactivities of the lipids wer estimated in the same manner as in the previou experiments.

Organic acids in the liver were isolated by th method of Bryant et al.3! A liver specimen weighin $4 \mathrm{~g}$, which had been pooled from 4 rats, was ho mogenized with $25 \mathrm{ml}$ of $95 \%$ ethanol solution an centrifuged at $10,000 \times g$ for $10 \mathrm{~min}$. The resultan supernatant was evaporated under reduced pressur and dissolved in approximately $10 \mathrm{ml}$ distilled water This solution was passed through Amberlite IRA 40 and then $60 \mathrm{ml}$ of distilled water was passed to remov sugars and amino acids. After elution with $25 \mathrm{ml}$ o $1 \mathrm{~N}$ ammonium carbonate, the solution containing th acids and excess elutant were evaporated to dryness and the residue was brought to the required volum with distilled water. This concentrated extract wa chromatographed on Toyo Roshi No. 50 filter pape by using ascending chromatography with a solven system of butanol/formic acid/water $(10: 2: 15)$. Th chromatogram was scanned for radioactivity by thi Aloka JPL-105 radioactive chromatogram counter, anc to identify the acids $0.04 \%$ chlorophenol red solution in ethanol41 was used as the indicator for the standare acids.

\section{RESULTS}

Experiment 1. The incorporation of ${ }^{14} \mathrm{C}$ into $r e$ spiratory carbon dioxide and the lipids of th liver and carcass, and the concentration of $n u$ cleotides in the liver $1 \mathrm{hr}$ after injection o acetate- $1{ }^{14} \mathrm{C}$ following $2 \mathrm{hr}$ feeding with nutrient The results presented in Table I show th relative recovery ratio of ${ }^{14} \mathrm{C}$ in the respirator: carbon dioxide, the lipids of the liver and thosi of carcass. The feeding of starch resulted is

3) F. Bryant and B. T. Overell, Biochim. Biophys Acta, 10, 471 (1953).

4) R. J. Block, E. L. Durrum and G. Zweig, "A Manual of Paper Chromatography and Paper Elec trophoresis", Academic Press Inc., New York, N.Y. 1955, p. 169. 
increase in the incorporation into the lipids of the liver and carcass, but the feeding of casein or corn oil did not cause any significant alteration. The level of glycogen in the liver was markedly elevated with the feeding of starch.

The concentration of nucleotides in the liver is given in Table II. In comparing the level of nucleotides, it seemed preferable to calculate the relative value of each nucleotide. This value was expressed as percentage to the level of ADP, which was relatively constant against changes in the dietary components. Table III shows these relative values of nucleotides. The feeding of starch induced marked changes in the level of nucleotides. The level of ATP and the sum total of GTP and UTP increased with the feeding of starch, but decreased a little or was unaffected with the feeding of casein or corn oil. On the other hand, the

TABLE I. EFFects of DIETaRy STaRch, Casein OR CORN OIL ON INCORPoration of ${ }^{14} \mathrm{C}$ of Acetate-1-14C INTO Respiratory CaRbon DIOXIDE, AND LIVER AND CARCASS LIPIDS ${ }^{11}$

$\begin{array}{lcccrr} & \text { No. of rats } & \begin{array}{c}\text { Liver } \\ \text { glycogen } \\ \% \text { of } \\ \text { wet wt. }\end{array} & \begin{array}{c}\text { Relative recovery ratio } \\ \text { Respiratory } \\ \mathrm{CO}_{2} \%\end{array} & \begin{array}{c}\text { Liver lipids } \\ \%\end{array} & \begin{array}{c}\text { Carcass lipids } \\ \%\end{array} \\ \text { Before feeding } & 5 & 0.45 \pm 0.30^{31} & 95.6 \pm 0.9 & 0.4 \pm 0.12 & 4.0 \pm 0.60 \\ \text { Starch } & 5 & 4.76 \pm 0.69 & 70.0 \pm 1.8 & 8.6 \pm 2.28 & 21.4 \pm 2.81 \\ \text { Casein } & 5 & 0.25 \pm 0.09 & 93.7 \pm 1.0 & 1.9 \pm 0.96 & 4.4 \pm 0.75 \\ \text { Corn oil } & 5 & 0.21 \pm 0.08 & 95.4 \pm 1.2 & 0.5 \pm 0.10 & 4.1 \pm 1.18\end{array}$

1) Rats were allowed to gain access to feed for $2 \mathrm{hr}$, prior to injection with acetate-1 $-14 \mathrm{C}$ being housed in a metabolic chamber for $1 \mathrm{hr}$.

2) The ratio of radioactivity in each of the three fractions, i.e., the respiratory carbon dioxide, and lipids of the liver, and those of the carcass, to the sum total of radioactivity found in these three fractions.

3) Mean \pm S. E.

TABle II. Concentrations of NuCleotides IN LIVer AFter Feeding of Nutrients ${ }^{1}$

\begin{tabular}{|c|c|c|c|c|c|c|c|c|c|c|c|}
\hline & CMP & AMP & GMP & IMP & UMP & ADP & $\begin{array}{l}\text { UDPGlcNAc }{ }^{21} \\
\quad+\text { UDPGlc } \\
\text { moles/g }\end{array}$ & GDP & UDP & ATP & $\begin{array}{r}\text { GTP } \\
+ \text { UTP }\end{array}$ \\
\hline Before feeding & $0.11^{31}$ & 1.78 & 0.21 & 0.30 & 0.76 & 1.45 & 1.35 & 0.29 & 0.52 & 0.90 & 0.31 \\
\hline Starch & 0.19 & 1.08 & 0.17 & 0.23 & 0.39 & 1.28 & 0.55 & 0.24 & 0.23 & 1.52 & 0.43 \\
\hline Casein & 0.18 & 2.03 & 0.23 & 0.23 & 0.85 & 1.48 & 1.17 & 0.24 & 0.27 & 0.90 & 0.28 \\
\hline Gorn oil & 0.19 & 2.47 & 0.35 & 0.41 & 0.80 & 1.60 & 1.05 & 0.21 & 0.27 & 0.82 & 0.2 \\
\hline
\end{tabular}
killing.

1) Rats were allowed to gain access to feed for $2 \mathrm{hr}$, and then kept away from food for $1 \mathrm{hr}$, prior to

2) UDP-N-acetylglucosamine and UDP-glucose.

3) Each experiment was carried out with pooled liver of 5 rats.

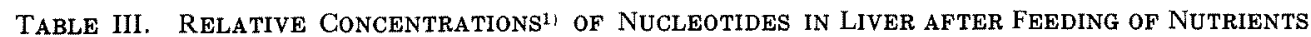

$\begin{array}{lccccccccccc} & \text { CMP } & \text { AMP } & \text { GMP } & \text { IMP } & \text { UMP } & \text { ADP } & \begin{array}{c}\text { UDPGlcNAc } \\ \text { +UDPGlc }\end{array} & \text { GDP } & \text { UDP } & \text { ATP } & \begin{array}{c}\text { GTP } \\ \text { +UTP }\end{array} \\ \text { Before feeding } & 8 & 126 & 14 & 21 & 52 & 100 & 93 & 20 & 36 & 62 & 22 \\ \text { Starch } & 15 & 85 & 13 & 18 & 30 & 100 & 43 & 18 & 18 & 119 & 33 \\ \text { Casein } & 12 & 137 & 15 & 15 & 56 & 100 & 79 & 16 & 18 & 61 & 19 \\ \text { Corn oil } & 12 & 155 & 22 & 26 & 50 & 100 & 66 & 38 & 17 & 52 & 14\end{array}$

1) The concentration of ADP is taken as the standard for nucleotide concentrations, which are shown in Table II.

2) UDP-N-acetylglucosamine and UDP-glucose. 
level of AMP and UMP decreased with the feeding of starch, but increased a little or was not changed at all with the feeding of casein or corn oil.

Experiment 2. Periodic changes in the level of $A T P$ and $A M P$ in the liver after feeding starch or casein

After the feeding of starch, the concentration of ATP increased at $4 \mathrm{hr}$ and then declined gradually till $20 \mathrm{hr}$, but the concentration of AMP decreased at $4 \mathrm{hr}$ and increased gradually till $20 \mathrm{hr}$ after feeding (Table IV). After the feeding of casein, however, the concentrations of ATP and AMP showed a trend nearly reverse to those of the feeding of starch till $8 \mathrm{hr}$.

Table IV. Changes in Relative ConcentraTIONS ${ }^{1 !}$ OF ADENINE NUCLEOTIDES IN LIVER OF Rats WITH TIME AFTER FEEDING OF STARCH OR CASEIN

Before feeding

AMP

$4 \mathrm{hr}$ after feeding of starch

$8 \mathrm{hr}$ after feeding of starch

$20 \mathrm{hr}$ after feeding of starch

$4 \mathrm{hr}$ after feeding of casein

$8 \mathrm{hr}$ after feeding of casein

$20 \mathrm{hr}$ after feeding of casein standard for nucleotide concentrations.

2) Each experiment was carried out with pooled liver of 5 rats.

Experiment 3. Changes in the concentration of citric acid in the liver after feeding with nutrients Table $V$ shows the concentration of citric acid in the liver $3 \mathrm{hr}$ after the feeding of starch, casein, or corn oil. The concentration of citric acid following the feeding of casein or corn oil was nearly the same as that before the feeding. The feeding of starch, however, caused a significant reduction in the concentration of citric acid.
Table V. Concentration of Citric Acid IN LIVER AFTER FEEDING OF NUTRIENTS1?

$\begin{array}{lcc} & \text { No. of rats } & \text { Citric acid } \times 10^{-4} \mathbf{M} \\ \text { Before feeding } & 4 & 2.4 \pm 0.32^{2} \\ \text { Starch } & 4 & 1.3 \pm 0.11 \\ \text { Casein } & 4 & 2.7 \pm 0.11 \\ \text { Corn oil } & 4 & 2.6 \pm 0.30\end{array}$

1) Rats were allowed to gain access to feed for $2 \mathrm{hr}$, and then kept away from food for $1 \mathrm{hr}$, prior to killing.

2) Mean \pm S. E.

Experiment 4. Changes in the metabolism of citric acid- $1,5{ }^{14} \mathrm{C}$ after feeding with nutrients

Since the concentration of citric acid in the liver had been found to vary with the dietary component, the metabolism of citric acid was investigated in this experiment. Table VI shows the relative recovery of ${ }^{14} \mathrm{C}$ from the carbon dioxide, the liver, and carcass $30 \mathrm{~min}$ after injection with citric acid-1,5- ${ }^{14} \mathrm{C}$ which had been made $2 \mathrm{hr}$ after feeding with nutrients. The incorporation of ${ }^{14} \mathrm{C}$ into the respiratory carbon dioxide was greater and that into the liver and carcass was smaller in rats given starch than in those given corn oil or casein, and those before feeding. Almost all the radioactivity in the liver of rats fed starch, casein or corn oil was found in the 5\%-TCAsoluble fraction and in the lipids. Although the incorporation of ${ }^{14} \mathrm{C}$ into the liver was a little smaller in the rats given starch than in those of any other group, the incorporation of ${ }^{14} \mathrm{C}$ into the lipids of the liver was extremely greater in the rats given starch than in those given casein or corn oil. The same, but not so remarkable, trend was observed in the lipids of the carcass.

Figure 1 shows the radiopaperchromatogram of the organic acid fraction of the liver $30 \mathrm{~min}$ after injection with citric acid-1,5- ${ }^{14} \mathrm{C}$ performed $2 \mathrm{hr}$ after feeding the nutrients. In it, the highest peak of radioactivity was identified as citric acid. Accordingly, it was assumed that citric acid-1,5- ${ }^{14} \mathrm{C}$ had entered the liver almost as itself, and that it had hardly been metabolized into any other component of the organic acid $30 \mathrm{~min}$ after injection. 
Table VI. Metabolism of CItric AcId-1,5-14C after Feeding of Nutrientsil

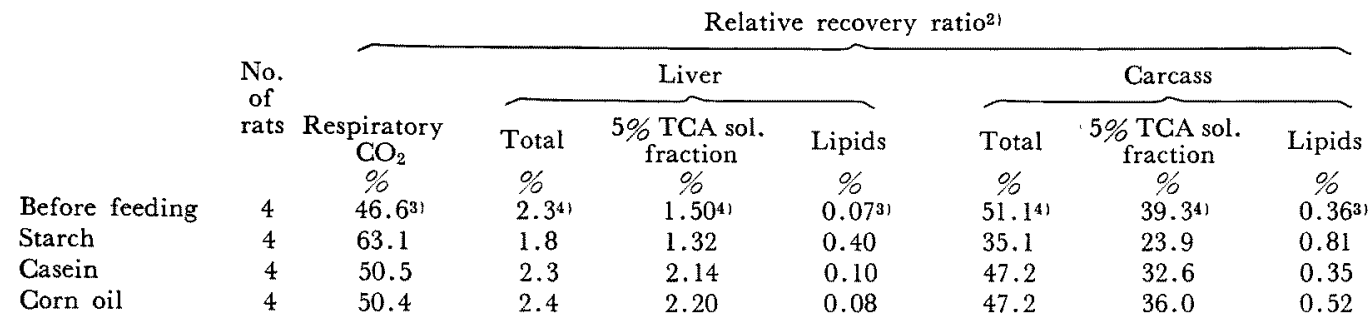

1) Rats were allowed to gain access to feed for $2 \mathrm{hr}$, prior to injection with citric acid-1,5-14C, being housed in is metabolic chamber for $30 \mathrm{~min}$.

2) The ratio of radioactivity in each of the seven fractions to the sum total of radioactivity found in the three fractions, i.e., the respiratory carbon dioxide, the liver, and the carcass.

3) Average value of 4 rats.

4) From pooled liver or carcass of 4 rats.

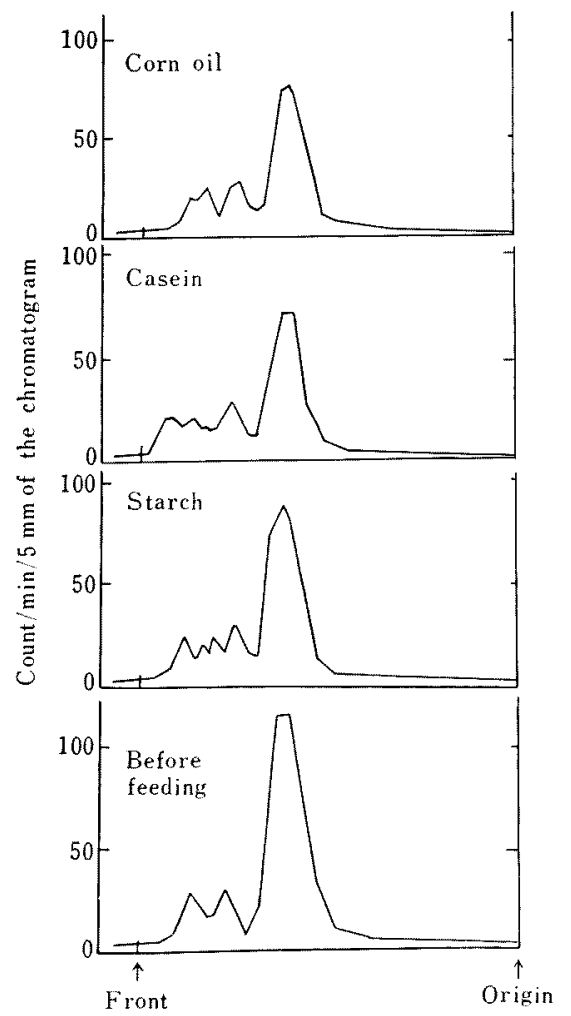

FIG. 1. Radioactivity on Paper Chromatogram of Organic Acid Fraction of Liver after Feeding of Nutrients.

The method is described in the text.

\section{DISCUSSION}

In the present experiments, when the stimuIation of lipogenesis in the liver was caused by the feeding of starch, the concentration of ATP nearly doubled and the concentration of citric acid reduced to half. On the other hand, the feeding of casein or corn oil, or fasting failed to stimulate lipogenesis in this organ (Table II and V). These observations suggest that there may be a correlation between lipogenesis in the liver and the changes of the concentration of ATP and citric acid in this organ in the rats fed individual nutrients, such as carbohydrate, fat or protein, as in the previous study, ${ }^{1}$ in which lipogenesis was stimulated with an increase in starch content both in the starch-casein and starch-corn oil diets. From these facts, the changes in lipogenesis with time after the feeding of starch or casein may be supposed by the periodic changes of the concentration of ATP in the liver shown in Table IV

It was also observed in the previous study ${ }^{11}$ that there was a rapid drop in lipogenesis in the liver with an increase in corn oil content in the starch-corn oil diets, while lipogenesis decreased gradually with an increment in casein content in the starch-casein diets. These finding could be explained by the present data that the feeding of fat has little effect 
on lipogenesis in the liver, whereas the feeding of casein led to low stimulation in lipogenesis in this organ (Table I).

The incorporation of ${ }^{14} \mathrm{C}$ of citric acid-1,5${ }^{14} \mathrm{C}$ into the lipids of the liver was higher with the feeding of starch than with that of casein or corn oil, as shown in Table VI. This finding seems to be consistent with the changes in the activity of citrate-cleavage enzyme in the liver of animals fed experimental diets as reported by Kornacker and Lowenstein. ${ }^{5,6)}$ The citrate-cleavage enzyme was suppressed on starvation and restored on refeeding after starvation. The increase in

5) M.S. Kornacker and J. M. Lowenstein, Biochem. $J ., 94,209$ (1965).

6) M.S. Kornacker and J.M. Lowenstein, ibid., 95, $832(1965)$. enzyme activity that occurred on refeeding depended on the diet. It was largest on feeding a high carbohydrate and low fat diet, and smallest on feeding a high fat diet. The changes in activity of citrate-cleavage enzyme was correlated with fatty acid synthesis. On the other hand, Srere and Foster ${ }^{71}$ proposed recently that no suppressed lipogenesis in starvation might be due to decreased levels of citrate-cleavage enzyme. The data of Table VI indicate that the feeding of starch stimulated citrate to be converted to lipids and carbon dioxide, although the primary cause of this conversion remains obscure.

7) P. A. Srere and D. W. Foster, Biochem. Biophys. Res. Comm., 26, 556 (1967). 